\title{
Multiband hairpin-line bandpass filters by using metamaterial complimentary split ring resonator
}

\author{
Mohd Fairus Mohd Yusoff, Muhammad Akram Mohd Sobri, Farid Zubir, Zaharah Johari \\ School of Electrical Engineering, Universiti Teknologi Malaysia, Malaysia
}

\begin{tabular}{|c|c|}
\hline Article Info & ABSTRACT \\
\hline Article historys: & Telecommunication systems for the new generation have greatly stimulated \\
\hline Received Mar 27, 2019 & $\begin{array}{l}\text { the demand for multi-band bandpass filters with compact dimensions, } \\
\text { low insertion loss, robust, low cost and less complex design. In this paper, }\end{array}$ \\
\hline Revised May 6, 2019 & a compact multi-band bandpass filter, with the fractional bandwidth of $40 \%$ \\
\hline Accepted May 29, 2019 & $\begin{array}{l}\text { and } 20 \% \text { at resonant frequency } 3.5 \text { and } 5.5 \mathrm{GHz} \text { respectively with the response } \\
\text { of Chebyshev passband ripple of } 0.1 \mathrm{~dB} \text { is presented. This bandpass filter is }\end{array}$ \\
\hline Keywords: & $\begin{array}{l}\text { suitable for WiMAX application. The design is based on the hairpin-line } \\
\text { configuration and metamaterial of complementary split ring resonator }\end{array}$ \\
\hline Bandpass & structure. The hairpin-line is used for the compact structure design and easy to \\
\hline $\begin{array}{l}\text { Complimentary split ring } \\
\text { resonator (CSRR) }\end{array}$ & $\begin{array}{l}\text { While the complementary split ring resonator structure is easy to design and } \\
\text { can provide multi-band without affecting of size and performance of the filter. }\end{array}$ \\
\hline Hairpin-line & The simulated results show the dual-band bandpass response with the insertion \\
\hline Metamaterial & loss is $0 \mathrm{~dB}$ and high attenuation at stopband. The proposed filter provides a \\
\hline Multi-band & $\begin{array}{l}\text { compact, low insertion loss, and less complex structure design that are } \\
\text { promising candidates in order to meet the demands of the new generation of } \\
\text { communication systems. }\end{array}$ \\
\hline
\end{tabular}

Copyright (C) 2019 Institute of Advanced Engineering and Science. All rights reserved.

\section{Corresponding Author:}

Mohd Fairus Mohd Yusoff, School of Electrical Engineering, Universiti Teknologi Malaysia, 81310 UTM Skudai, Johor, Malaysia.

Email: mdfairus@utm.my

\section{INTRODUCTION}

The development of the telecommunication systems have enhanced the requirement for more sophisticated devices in order to meet the demands of the new generation of communication systems. In recent years, most of the wireless communication systems require a multifunctional device that can be operated in two or more frequency bands, small size, compact, robust and low cost. For example, the WiMAX applications that can be operate dual frequency band which are $3.5 \mathrm{GHz}$ and $5.5 \mathrm{GHz}$. In the wireless systems, transmitterreceiver or transceiver is an important device that transmits and receives the modulated signal through a transmission medium. Multi-band transceiver components, such as multi-band bandpass filter, amplifier and oscillator are key devices to reduce the cost and the size of a multi-standard wireless system. In this paper, a multi-band bandpass filter has been proposed. The challenges to circuit designers designing a multiband bandpass filter are to achieve a small size and low insertion loss simultaneously. The previous researchers, the structure of multi-band filters design very complexly because have too many components inside and high insertion loss [1-4].

The hairpin-line band-pass filter is one of the most popular microstrip filter configurations used for the compact structure. This design is easy to fabricate because it has open-circuited ends that require no grounding. This design is obtained by folding the resonators of parallel-coupled into a "U" shape. This configuration will reduce the length of the conventional parallel-coupled band-pass filter. The examples 
of previous work that using hairpin-line and interdigital configuration to design a compact filter have been reported in [5-7]. The size of the filter is $82.04 \mathrm{~mm} \times 48.50 \mathrm{~mm}$ and has a more compacted structure compare to the conventional parallel-coupled method [6]. In addition, the hairpin filter can greatly improve the frequency selectivity compared with parallel-coupled structure [7].

Recently, many researchers have been attracted by a new type of artificial materials called as metamaterials. The metamaterials are a material engineered to have electromagnetic properties that are not found in nature [8-10]. The metamaterials have effective negative permittivity $(\varepsilon)$ and negative permeability $(\mu)$ which was theoretically investigated by a Russian scientist Vaselago [11]. In RF and microwave engineering, in order to obtain properties not present in the conventional material, the metamaterial transmission lines have been proposed. Metamaterial transmission line is an artificial line consisting of a host line such as a microstrip and coplanar waveguide (CPW) loaded with reactive elements such as inductances, capacitance or resonator [12-13]. Metamaterials are implemented with a split ring resonator (SRR) and complementary split ring resonator (CSRR) [14-16]. The advantages of CSRRs and SRRs are to reduce circuit dimension because the dimension of these resonators is much smaller than the signal wavelength at resonance. The previous researchers have been proved that by using metamaterial of CSRR can provide a compact design and without affecting the performance of filters [17-19].

In this paper, the metamaterials of CSRR have been studied to be used as a band-pass or band-stop filter. Then the CSRRs structure is combined with the hairpin-line bandpass filter to produce multi-band frequency responses. A proposed multi-band bandpass filter has provided compact size, less complex design with low insertion loss and high attenuation at stopband.

\section{FILTER DESIGN}

The proposed multi-band filter is designed in the following steps. The first step is to design a wide bandpass filter covering the frequency from 3.5 to $6.5 \mathrm{GHz}$ by using hairpin-line configuration. The second step is to design a bandstop and bandpass filter at frequency $5 \mathrm{GHz}$ based on CSRR configuration. The third step is to integrate the hairpin-line filters with the CSRR bandstop filter to result in a dual-band bandpass filter. This will be explained in details in the following.

\subsection{Hairpin-line filter design}

The conventional wideband hairpin-line bandpass filter was designed at a resonant frequency of 5 $\mathrm{GHz}$, fractional bandwidth of $66 \%, 5$ poles design, and the response of Chebyshev with passband ripple of 0.1 $\mathrm{dB}$. The rogers RT6006 is used as substrate with a dielectric constant 6.15 . The hairpin structure was designed by using copper as conducting element with thickness, $\mathrm{t}$ is $0.035 \mathrm{~mm}$.

The element values for Chebyshev function low-pass prototype filters was obtained from Table 1, given for a normalized low-pass cut-off frequency $\Omega_{-} \mathrm{c}=1$, are g0 $=\mathrm{g} 6=1.0$, g1 $=\mathrm{g} 5=1.1468$, g2 $=\mathrm{g} 4=$ 1.3712 and $\mathrm{g} 3=1.9750$. The physical dimensions of hairpin-line in Figure 2 are calculated by using the following formulas [20].

$$
\begin{aligned}
& Q_{e 1}=\frac{g_{0} g_{01}}{F B W}, Q_{e n}=\frac{g_{0} g_{01}}{F B W} \\
& M_{i, i+1}=\frac{F B W}{\sqrt{g_{i} g_{i+1}}} \text { for } i=1 \text { to } n-1
\end{aligned}
$$

\begin{tabular}{ccccccc}
\multicolumn{6}{c}{ Table 1. Element values for Chebyshev lowpass prototype filters [20] } \\
\hline $\mathrm{N}$ & $\mathrm{G} 1$ & $\mathrm{G} 2$ & $\mathrm{G} 3$ & $\mathrm{G} 4$ & $\mathrm{G} 5$ & $\mathrm{G} 6$ \\
\hline 1 & 0.3052 & 1.0 & & & & \\
2 & 0.8431 & 0.6220 & 1.3554 & & & \\
3 & 1.0316 & 1.1474 & 1.0316 & 1.0 & & \\
4 & 1.1088 & 1.3062 & 1.7704 & 0.8181 & 0.3554 & \\
5 & 1.1468 & 1.3712 & 1.9750 & 1.3712 & 1.1468 & 1.0 \\
\hline
\end{tabular}

Where Q_e1 and Q_en are the external quality factors of the resonators at the input and output, and M_(i,i+1) are the coupling coefficients between the adjacent resonators. The hairpin resonators as shown in Figure 1 have a line width of $1 \mathrm{~mm}$ and a separation of $2 \mathrm{~mm}$ between the two arms.

A design equation is proposed for estimating the tapping point, $t$ as shown below [20], in which $Z_{r}$ is the impedance of the hairpin line, $Z_{o}$ is the terminating impedance, and $\mathrm{L}$ is about $\lambda_{g_{0}} / 4$ long. Figure 2 shows all physical dimensions of hairpin-line bandpass filter operate at frequency $5 \mathrm{GHz}$. 


$$
t=\frac{2 L}{\pi} \sin ^{-1}\left(\sqrt{\frac{\pi}{2} \frac{Z_{o} / Z_{r}}{Q_{e}}}\right)
$$

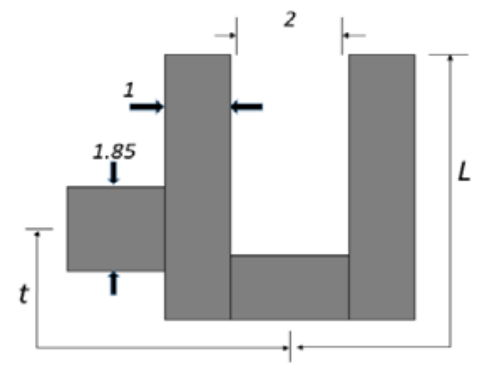

Figure 1. Hairpin resonator

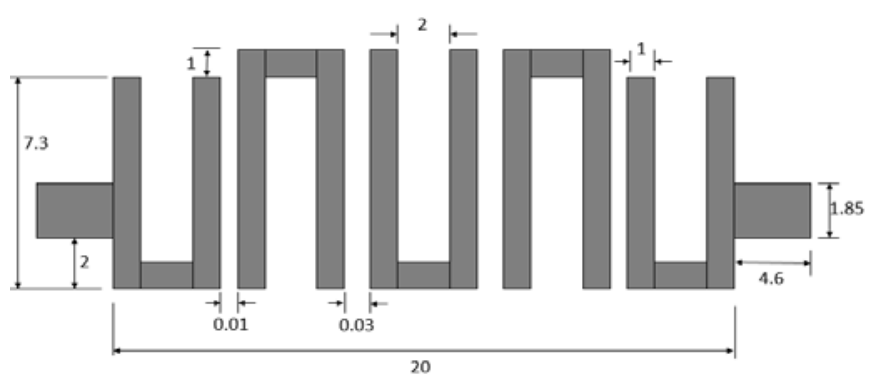

Figure 2. Geometry of hairpin-line structure at frequency $5 \mathrm{GHz}$

\subsection{Multi-band bandpass filter design}

The unit cell of CSRRs as shown in Figure 3 was designed at resonant frequency $5 \mathrm{GHz}$, using Rogers RT6006 as a substrate with a thickness of $1.27 \mathrm{~mm}$, a relative permittivity of 6.15 , and a loss tangent of 0.025 . From the Figure 3, the conducting lines at top layer have a series gap and without a series gap.
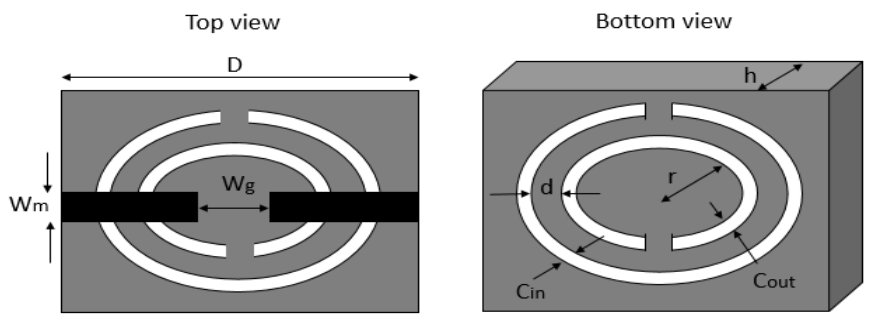

(a)
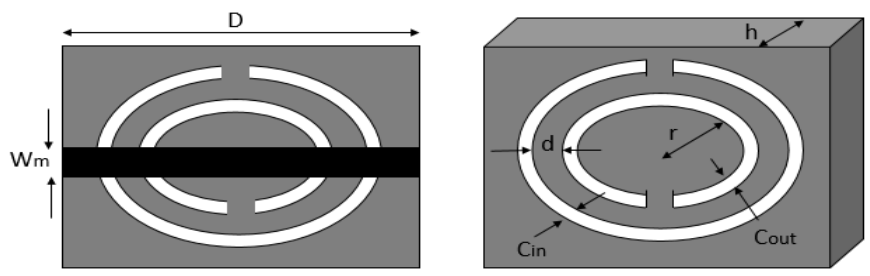

(b)

Figure 3. Unit cell of CSRRs with a series gap (a) and without series gap (b)

Table 2 shows all parameters of a unit cell CSRR in Figure 3. The values of the parameters are slightly different compared to the theoretical calculation to reach the design specification.

Table 2. Dimensions of unit cell CSRR

\begin{tabular}{ccc}
\hline Parameters & Symbol & Value $(\mathrm{mm})$ \\
\hline Length of conducting line & $\mathrm{D}$ & 8 \\
Width of conducting line & $\mathrm{W}_{\mathrm{m}}$ & 1 \\
Length of series gap & $\mathrm{W}_{\mathrm{g}}$ & 0.4 \\
Inner radius of the first ring & $\mathrm{r}$ & 1.26 \\
Width of the first ring & $\mathrm{C}_{\text {in }}$ & 0.366 \\
Width of the second ring & $\mathrm{C}_{\text {out }}$ & 0.364 \\
Gap between the ring & $\mathrm{d}$ & 0.4 \\
\hline
\end{tabular}




\subsection{Multi-band bandpass filter design}

The multiband metamaterial hairpin-line bandpass filter was designed to resonate at $3.5 \mathrm{GHz}$ and 5.5 GHz. Rogers RT6006 is used as a substrate with a thickness of $1.27 \mathrm{~mm}$ and a relative permittivity of 6.15 . The filter specification is design to be 5 poles with the fractional bandwidth of $40 \%$ and $20 \%$ and using the response of Chebyshev with passband ripple $0.1 \mathrm{~dB}$.

Figure 4 shows the proposed multiband bandpass filter configuration that combine wideband hairpin filter with three unit cell CSRR metamaterial. From the picture, the yellow color is a hairpin structure at the top layer and the red color is CSRRs at the ground plane. The conventional wideband hairpin-line bandpass filter and CSRR unit cell was designed to resonate at $5 \mathrm{GHz}$.

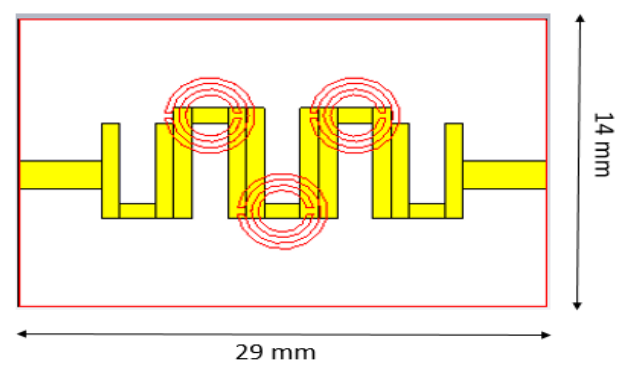

Figure 4. Multiband metamaterial hairpin-line bandpass filter

\section{RESULTS AND DISCUSSION}

Figure 5 shows the simulation results of the conventional wideband hairpin bandpass filter that simulate by using CST Software. It can be seen that the center frequency for hairpin filter is $5 \mathrm{GHz}$ with bandwidth of $3.32 \mathrm{GHz}$. At the center frequency, the insertion loss, S2 1 is $0 \mathrm{~dB}$ and the attenuation loss at upper and lower cut off frequency are greater then $-10 \mathrm{~dB}$. Meanwhile, the return loss, $\mathrm{S} 11$ is less than $-10 \mathrm{~dB}$, so this wideband hairpin filter has good performances.

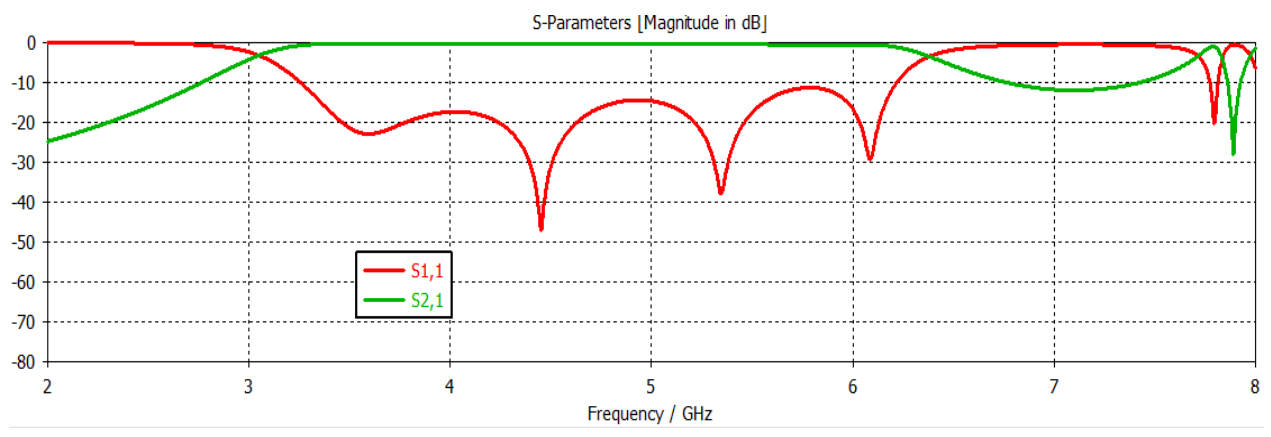

Figure 5. Simulation result of conventional hairpin filter

Figure 6 shows the simulation result of unit cell CSRR with a series gap and without a series gap. The s-parameter result shows the bandpass characteristic response of the CSRR with the series gap configuration at $5 \mathrm{GHz}$ and the bandwidth is around $400 \mathrm{MHz}$ as shown in Figure 6 (a). While, the CSRR without a series gap shown a bandstop characteristic at $5 \mathrm{GHz}$ with bandwidth around $500 \mathrm{MHz}$ as shown in Figure 6 (b). However, based on these results, the filter performances for single CSRR unit cell is not very good especially for bandpass filter because at the upper cut-off frequency the attenuation loss is lower. Thus, to solve this problem, three CSRRs unit cell is added in cascade to increase the attenuation loss at upper frequency.

Figure 7 shows the simulation results of multiband metamaterial hairpin bandpass filter. From the simulation results, the center frequency of passband is around $3.5 \mathrm{GHz}$ at the first band and around $5.5 \mathrm{GHz}$ for the second band. The insertion loss for the both passband is $0 \mathrm{~dB}$. Moreover, the bandwidth at first band is around $1.9 \mathrm{GHz}$ and $1.2 \mathrm{GHz}$ for the second band. At the stop-band, the center frequency is $4.7 \mathrm{GHz}$ with the bandwidth of $500 \mathrm{MHz}$. The return loss, $\mathrm{S} 11$ at first and second passband is less than $-10 \mathrm{~dB}$. Then, the 
attenuation at stopband is very high at $-50 \mathrm{~dB}$ and the attenuation at upper frequency at second passband has been increased to $-20 \mathrm{~dB}$ compared to previous conventional hairpin filter. This show that we can design a dual band filter with improves performances by adding CSRRs metamaterial structure to conventional wideband hairpin filter.

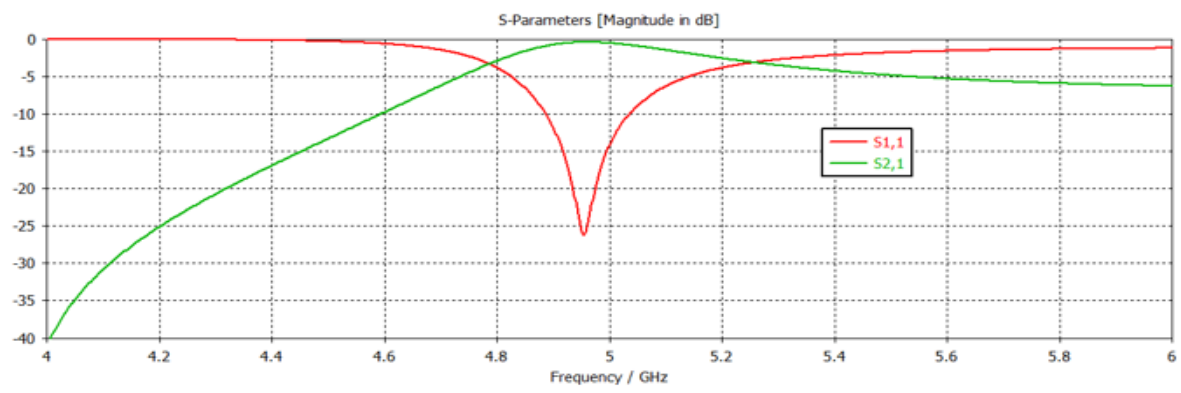

a) CSRR with series gap

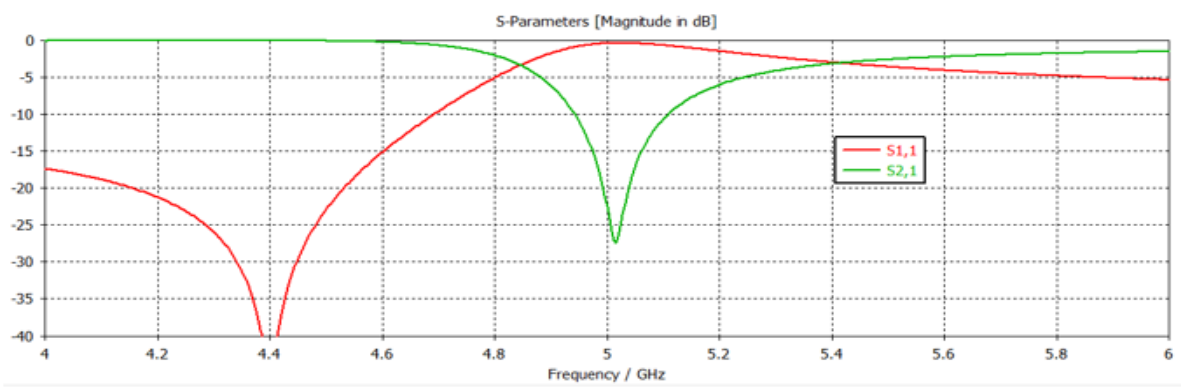

b) CSRR without series gap

Figure 6. Simulation results of unit cell CSRR

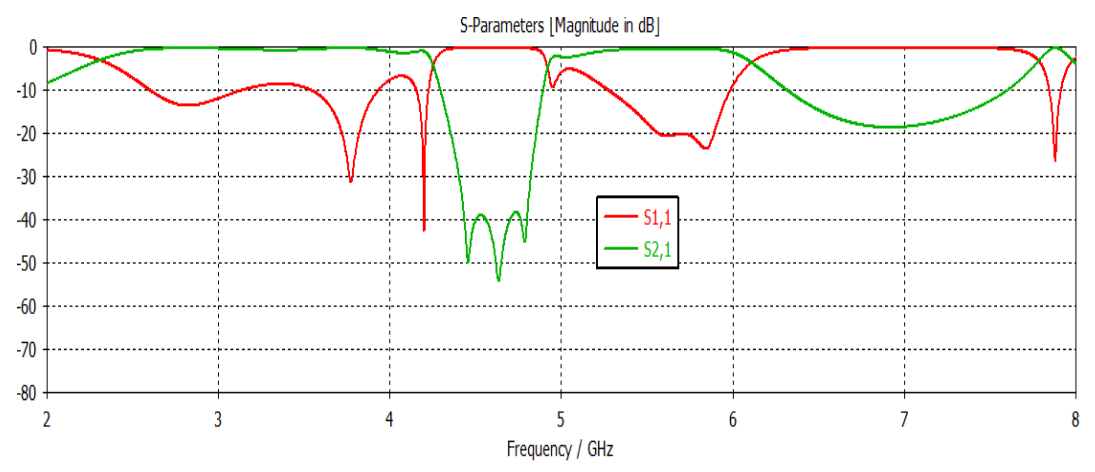

Figure 7. Simulation result of multiband metamaterial hairpin bandpass filter

Table 3 shows the comparison interms the performances and sizes of the proposed filter with the other reported designs. It can be seen that the size of the proposed filter is slightly bigger than the other filters but still can be considered compact. In addition, the performance of the proposed filter is much better than the other filters with lower insertion loss at desired passband as shown in Table 3.

Table 3. Comparison the proposed filter with the other reported

\begin{tabular}{llll}
\hline & f1 / insertion loss & f2 / insertion loss & Size \\
\hline$[3]$ & $3.5 \mathrm{GHz} / 2 \mathrm{~dB}$ & $5.5 \mathrm{GHz} / 2 \mathrm{~dB}$ & $19 \mathrm{~mm} \times 16.65 \mathrm{~mm}$ \\
{$[4]$} & $3.5 \mathrm{GHz} / 1.1 \mathrm{~dB}$ & $5.75 \mathrm{GHz} / 0.89 \mathrm{~dB}$ & $19 \mathrm{~mm} \times 12 \mathrm{~mm}$ \\
Proposed filter & $3.5 \mathrm{GHz} / 0 \mathrm{~dB}$ & $5.5 \mathrm{GHz} / 0 \mathrm{~dB}$ & $29 \mathrm{~mm} \times 14 \mathrm{~mm}$ \\
\hline
\end{tabular}

Multiband hairpin-line bandpass filters by using metamaterial complimentary ... (Mohd Fairus Mohd Yusoff) 


\section{CONCLUSION}

In this paper, a unit cell CSRR operating at $5 \mathrm{GHz}$ has been successfully designed and analyzed. From the results, it can be concluded that a unit cell CSRR with a series gap has the bandpass characteristic and a unit cell CSRR without a series gap has the bandstop characteristic. The result performances of single CSRR can be improved by adding more CSRRs unit cells in cascade. Finally, a multiband metamaterial hairpin bandpass filter operating at 3.5 and $5.5 \mathrm{GHz}$ has been presented. The proposed multiband bandpass filter has better performances compared to the conventional hairpin filter design.

\section{ACKNOWLEDGMENTS}

The authors would like to thank the Ministry of Higher Education (MOHE) Malaysia, Research Management Centre (RMC), School of Electrical Engineering, Universiti Teknologi Malaysia (UTM) for supporting the research work under grant number: $14 \mathrm{~J} 22$.

\section{REFERENCES}

[1] Chen C. F, Huang T.Y., and Wu R. B., "Design of Dual-and Triple-Passband Filters Using Alternately Cascaded Multiband Resonators," IEEE Transactions on Microwave Theory and Techniques, vol. 54(9), pp. 3550-3558, 2006.

[2] Feng Y, Guo X, Cao B, Wei B, Zhang X, Song F, Lu X., and Xu, Z., "Tri-band Superconducting Bandpass Filter with Controllable Passband Specifications," Electronics Letters, vol. 50(20), pp. 1456-1457, 2014.

[3] Pal M, Chatterjee J., and Ghatak R. A., "Compact Dual Band Bandpass Filter for WLAN/Wimax Application," in Applied Electromagnetics Conference (AEMC), IEEE, pp. 1-3, 2011.

[4] Kamma A, Reddy G.S, Parmar R. S., and Mukherjee J., "Dual-Band Filter for WIMAX and WLAN with Improved Upper Stop Band Performance," Progress in Electromagnetics Research, vol. 50, pp. 131-138, 2014.

[5] Bu, Q., Ding, J. and Guo, C. J., "New design of ultra-wideband bandpass filter using interdigitated-coupled lines CRLH-TL structure," Antennas, Propagation \& EM Theory (ISAPE), 2012 10th International Symposium on IEEE, pp. 486-489, 2012.

[6] Fadhil M, Wijanto H., and Wahyu Y., "Hairpin Line Bandpass Filter for 1.8 GHz FDD-LTE eNodeB Receiver," in Radar, Antenna, Microwave, Electronics, and Telecommunications (ICRAMET), International Conference, IEEE, spp. 134-136, 2017.

[7] Ye J, Qu D, Zhong X., and Zhou Y., "Design of X-Band Bandpass Filter Using Hairpin Resonators and Tapped Feeding Line," in Computer Applications and Communications (SCAC), IEEE Symposium, IEEE. 2014, pp. 93-95.

[8] Nqui J, Zamora G, Paredes F, Bonache J., and Martín F., "Metamaterial Transmission Lines for Wireless Communications, Sensing and RFID. Microwave Symposium (MMS), 2014 14th Mediterranean, IEEE, pp. 1-6, 2014.

[9] Ekmekci, E. and Turhan-Sayan, G., "Metamaterial sensor applications based on broadside-coupled SRR and V-Shaped resonator structures," Antennas and Propagation (APSURSI), 2011 IEEE International Symposium on IEEE, pp. 1170-1172, 2011.

[10] Martín, F., "Metamaterials for wireless communications, radiofrequency identification, and sensors," ISRN Electronics, 2012. 2012.

[11] Veselago V., "Electrodynamics of Substances with Simultaneously Negative Electrical and Magnetic Permeabilities," Soviet Physics Uspekhi, vol. 10, pp. 509-514, 1968.

[12] Aznar F, Gil M, Siso G, Bonache J., and Martin F., "SRR-and CSRR-Based Metamaterial Transmission Lines: Modeling and Comparison," Signal Integrity and High-Speed Interconnects, IMWS 2009, IEEE MTT-S International Microwave Workshop Series, IEEE, pp. 49-52, 2009.

[13] Alburaikan, A., Aqeeli, M., Huang, X. and Hu, Z., "Miniaturized ultrawideband bandpass filter based on CRLH-TL unit cell," Microwave Conference (EuMC), 2014 44th European. IEEE, pp. 540-543, 2014.

[14] Gil M, Bonache J, Selga J, García-García J, and Martín F., "Broadband Resonant -Type Metamaterial Transmission Lines," IEEE Microwave and Wireless Components Letters, vol. 17(2), pp. 97-99, 2007.

[15] Syahral, M. and Munir, A., "Development of multiple elements of SRR based Bandpass Filter," Telecommunication Systems Services and Applications (TSSA), 2016 10th International Conference on IEEE, pp. 1-4, 2016.

[16] Rathore, V., Awasthi, S. and Biswas, A., "Design of compact dual-band bandpass filter using frequency transformation and its implementation with Split Ring Resonator Dual-band bandpass filter using SRR," Microwave Conference (EuMC), 2014 44th European. IEEE, pp. 949-952, 2014.

[17] Afkhami, A. and Tayarani, M., "Spurious response suppression in hairpin filter using CSRR merged in the filter structure," Progress In Electromagnetics Research C., vol. 11, pp. 137-146, 2009.

[18] Naghar A, Alejos A.V, Aghzout O, Falcone F., and Sanchez M. G. C., "Band Parallel Coupled Bandpass Flter with Harmonic Suppression Using Open Stub and CSRRs," Antennas and Propagation (EuCAP), 2015 9th European Conference on IEEE, pp. 1-2, 2015.

[19] Cheng Y, Zeng L., and Lu W., "A Compact CSRR - Based Dual-Mode Patch Bandpass Filter," in Advanced Materials and Processes for RF and THz Applications (IMWS-AMP), IEEE MTT-S International Microwave Workshop Series, IEEE, pp. 1-3, 2015.

[20] Wiley J., Sons. Editors. Microwave Engineering. Fourth Edition. Incorporated. 2013.

Indo. J. Elec. Eng. \& Inf, Vol.7, No. 2, June 2019: 289 - 294 